\title{
ISSUES IN DEVELOPING AN ONLINE ADVISORY SYSTEM FOR TEXT WRITERS
}

\author{
CAREL J. M. JANSEN
}

Utrecht University, The Netherlands

MICHAËL F. STEEHOUDER

University of Twente, The Netherlands

\begin{abstract}
An online advisory system is described which offers guidelines and recommendations for text writers. The system tries to meet two essential requirements: easy switching from the text processing software to the online advice, and optimal access which enables the user to find relevant materials as easy as possible. The authors describe some studies with prototypes of the system. An analysis of information-seeking behavior yields some fundamental issues to be investigated in order to improve the usefulness of the system in the future.
\end{abstract}

Nowadays it is hard to imagine a technical communicator not using an advanced word processor with features such as a spelling checker, automatic hyphenation, and a thesaurus. Using advanced authoring systems is becoming more and more a common practice.

One component of an advanced authoring system might be an online system providing help for textual and linguistic puzzles arising during the writing task. Professional writers are familiar with traditional dictionaries, grammars, style guides, publication guides, ISO-guidelines etcetera. But consulting such references can be very digressive and time-consuming. Many writers, when facing a linguistic problem or feeling uncertain on a spelling issue, try to avoid the problem. They choose another expression which does not bring up such problems, instead of taking a reference book out of their bookcase and looking up the required information. Moreover, the range of sources consulted by most writers

C 1994, Baywood Publishing Co., Inc. 


\section{CATS: REQUIREMENTS AND DESIGN}

Online advisory systems can only be expected to be effective if they have clear advantages compared to their hard copy counterparts. The most important advantage of online help should lie in the speed through which specific information can be found. Apart from the hardware capacity, two CATS requirements seem critical here.

1. It should be very easy to switch from the word processor to CATS and vice versa, and, if desired, to copy standard phrases or text blocks into the actual document.

2. An adequate 'access structure" should enable users to find the relevant information as quickly and smoothly as possible. The expression 'access structure' refers to the whole means that help the reader locate information: menus, keywords, content lists, hyperlinks, etc.

To attain easy switching from a word processing system to CATS and vice versa, CATS was initially designed as a memory-resident program, to be activated by pressing a specific key-combination. Thus the user could switch to CATS from any word processing system running under DOS. CATS then created a window on the screen, in which the online information was presented. If the cursor was in the upper half of the word processor's screen, the CATS window appeared on the lower part, and if the cursor was on the lower part, the help screen appeared on the upper part. This permitted the user to keep looking at the text he was writing. However, the user could enlarge the window if he wanted to, which made it possible to display more CATS information on the screen.

The new version of CATS has been developed as a Windows help file. So concurrent running of CATS and a word processor or copying of elements from CATS into the text has even become easier.

From the beginning, the developers of CATS have paid special attention to the access structure, which should provide optimal search support to the users of the system. Several features were built in to ensure this.

First, both versions of CATS allow context-sensitive searching. If users can come up with an adequate term or phrase describing the issue they seek, they can type this term or phrase in their text and activate CATS. If the term or phrase occurs in the index list of CATS, the corresponding information is displayed in the CATS window automatically.

If the user does not choose context sensitive help, then CATS is entered at the Main Menu, which shows its main topics as well as an option to activate the index.

In the Windows version of CATS there are several routes providing access to the information. Using a content list or index is standard in Windows help programs, but CATS allows full text search as well. The user can type any keyword in the help text section he is searching. Next, the system displays the titles of all sections containing that string. Now the user can decide which section to display. 
seems to be very limited. For instance, a survey by Lentz and De Vet among professional free lance writers in The Netherlands pointed out that most of them only consult the leading Dutch dictionary (Van Dale), the official Dutch spelling guide (Woordenlijst der Nederlandse Taal) and one leading textbook on sentence writing (Schrijfwijzer) [1].

One major advantage of an online help system would be that searching goes much faster than searching in books or other paper materials. Consequently, authors can be expected to be more willing to use it. Moreover, online information can easily be updated, expanded, and adapted to the individual needs of the user; thus it could also provide better quality.

On the grammatical and stylistic level, style checkers such as Grammatik 5 or Rightwriter seem to be convenient devices for writers. However, experiments indicated that such programs may be of little significance in practice. They signal only a small portion of real problems, and produce a considerable amount of false alarms (problems indicated by the program which are not real problems). ${ }^{1}$

Most grammar and style checkers not only consist of a diagnostic mechanism, but include also an advisory part, containing guidelines for grammar and style. Such advisory systems also exist apart from spelling and style checkers. Examples for English writers are Editorial Advisor and the software versions of the textbook Shipley Style Guide and Strunk \& White's Elements of Style.

In Utrecht such an advisory system for Dutch writers has been under development since 1991. The system is called CATS: an acronym for Computer Adviezen voor TekstSchrijvers (Computer Advice for Text Writers). CATS is a co-production of Niceware Utrecht and Utrecht University (Centre for Language and Communication). The first version of CATS was written in PDC-PROLOG and was running under $M S-D O S$ as a memory-resident program. Prototypes have been developed containing recommendations and guidelines concerning issues like how to write a readable text, how to write an adequate press release, and how to design an effective access structure for software manuals. Recently a CATSversion running under $M S$-Windows has been completed.

In this article we will discuss some issues concerning online advisory programs for writing tasks, using CATS as a reference. First we will discuss some basic task requirements and show how CATS was designed to meet them. Next, we will report some test results with different prototypes of CATS, and after that, we will discuss certain requirements in more detail, particularly those related to the accessibility of the system. Throughout we will illustrate these problems using a general model of information behavior. Finally, by way of conclusion, we will briefly consider future prospects for online advisory systems like CATS.

\footnotetext{
${ }^{1}$ For a review of relevant research, $\mathrm{cf}$. [2].
} 
Four professional technical writers, working for a leading software company in The Netherlands, tested the second prototype. Their job responsibilities included writing software manuals and other technical documents. They revised some parts of the first draft of a manual which was developed by one of their colleagues. The assignment included four tasks: 1) revising numbers and titles in chapters 1 and 2 of the manual, 2) revising the content list for these chapters, 3) constructing an index for chapter 20, and 4) formulating good page headers and page footers for chapters 15 and 16 . They were asked to think aloud while performing their tasks, and the computer screen was videotaped. With this method it was possible to keep track of their course of actions, including their uses of CATS. After the writers finished the tasks, they were asked to complete a questionnaire.

It turned out that the subjects activated the CATS system frequently, and that they were positive about the practical value of the online information. The most interesting observations were made with respect to the route followed by the subjects:

- Although CATS allowed for context sensitive searches (see above), the subjects almost never used that facility.

- The subjects mostly entered CATS via the content list in the Main Menu.

- The index was used very rarely. If it was, the subjects most often chose an unsuitable entry.

- Hyperlinks were used in almost all cases where they were appropriate with respect to the problem which caused consulting CATS.

\section{BARRIERS TO SUCCESSFUL INFORMATION SEEKING}

The Tanis study showed that in spite of the presence of several access structures in CATS, accessibility can still be an important stumbling block for the users of CATS. Therefore, a more profound study of this aspect of CATS seems necessary. As a basis for this, we used a model of information seeking behavior derived from the existing research literature. The model-a shortened version of the one published by Steehouder [5] — consists of five sub-tasks that form part of an information seeking task:

1. Detecting the need for information

2. Formulating the problem

3. Locating the relevant information

4. Understanding the information

5. Inferring an action plan

The model depicts the essential stages of a CATS consultation. Such a consultation will only take place if the writer feels the need of guidelines, suggestions or other support in his writing task. Next he has to find an appropriate descriptionfor instance a keyword-to define his needs and to use as an entry to the system. 
From each section the user can move through the help document in several directions. It is possible to move forward or backward (or: page up/page down), but it is also possible to jump to a higher level in the hierarchy of the online advisory text-assuming that this text is organized in a hierarchical structure. Both CATS versions offer the possibility to see the list of all previously displayed sections (the history). This feature enables the user to move back to such a section and re-read it.

Finally, an important feature in the access structure of both CATS versions is the application of hypertext as a device for navigating through the online information. Specified words may be highlighted-so-called hot spots. If the user moves the cursor to a hot spot and presses <Enter> (or 'clicks' a hot spot using the mouse), another section will be displayed which contains information relevant to the topic chosen.

\section{CATS: EXPERIENCES WITH PROTOTYPES}

So far we have described the CATS system as no more than an empty shell to be filled with information that may be useful for text writers. Until now, several working prototypes have been constructed and tested. These yielded useful ideas for optimizing the shell as well as identified requirements for the content of this kind of advisory system.

Schneider and Tanis, using the DOS version of CATS, developed a prototype advisory system on writing letters of application [3]. They opted for a hierarchical structure of the information, with a Main Menu representing the various parts of such a letter: beginning, opening, middle, ending, resume. Starting from this menu, the user could reach general or more specific recommendations for each part of the letter. Other options accessible from the Main Menu included more general stylistic advice on style, conventions, and layout. And finally, the Main Menu gave access to the index.

Eight subjects tested the prototype. They wrote an application letter using a word processor and consulting CATS whenever they felt it could be useful. In addition, they were asked to think aloud while performing this task. Afterwards they were interviewed on their opinions about various aspects of the advisory system they had been working with.

It turned out that all subjects frequently consulted CATS information, in particular the recommendations on content and structure of a letter of application. Guidelines on matters of style and lay-out were used somewhat less frequently. The advice was generally judged as relevant and sufficient for the given task. All subjects felt that using CATS had helped them write a better letter than they would normally have written. Pieter Tanis developed a second prototype system, again using the DOS version of CATS. It contained suggestions for optimizing the access structure of technical documentation: suggestions for numbering chapters and paragraphs, for constructing a content list, an index, a glossary, introductory sections, page headers and footers, titles and subtitles, and a title page. 
formulating should continue fluently and be undisturbed. If this is true, consulting CATS would possibly disturb the process. But would writers interrupt formulating processes to consult CATS? And if so, would that be a threat to the quality of the writing process? Detailed observational research is certainly needed to clarify this issue.

During the revision/editing phases of the writing process, CATS could help answer many questions which arise from the text produced so far. Many of these questions will probably refer to problems of grammar, style, spelling (as far as they are not yet solved by the spelling checker), and perhaps to publication conventions (e.g., references). However, it is probable that writers will often try to find a solution without using online help. For instance, when a writer is unsure whether an expression is grammatical or not, he can consult the online help, but he can also try to avoid the expression and reformulate the sentence.

\section{Formulating the Problem}

A major barrier to successfully using CATS will probably be finding the appropriate wording for the problem. The seriousness of problems in this stage is illustrated by the results of a study by Vernoy [6]. She presented a list of linguistic errors to forty-three Dutch writers (secretaries, journalists, professional writers, and engineers) and asked the subjects to name those errors. It turned out that the subjects used a wide variety of terms. Most errors were named in ten or more different ways. The official grammatical terms were used scarcely. When asked to choose an appropriate term from an index, most subjects chose a non-technical, exemplary entry. Only in four cases did more than 50 percent of the subjects choose the technical term.

Problems in finding the right keywords are not restricted to grammatical terminology; they occur in many information-seeking processes. Nas confronted twenty subjects (students) with twenty-six different problems that could arise while using a word processing system [7]. The subjects were asked to write down the keyword they would look up in the manual if they did not know how to solve the problem. On average, twelve different keywords for each problem were mentioned, while only two were mentioned in the online help of a major word processing system. Many keywords did not occur in the online help, or would lead the user to irrelevant information.

An interesting issue is whether users will formulate their problems as open questions or as verifications. Open formulations do not assume a preference, for instance: Should I put the adverb of time before or after the adverb of place? or What would be a good approach to illustrate this point? Verifications are mostly meant to test an existing idea: Am I right that numbered steps are better than a bulleted list to present this instruction? Presumably, closed questions will characteristically arise in revision/editing stages of the writing process, while open questions might occur during formulation as well as during revising/editing. 
Then he has to locate the relevant information within CATS, and to interpret this information. However, it is not sufficient to understand the information; the writer also has to consider how the guidelines and recommendations can be applied in the text he is writing: he has to infer an action plan.

Each step in the model can become an obstacle for a successful consultation of CATS. Some examples from the first three steps of the model follow.

\section{Detecting the Need for Information}

First, there is the question whether writers will always be aware of their information needs. In other words: do they realize that it would be useful to consult online help? We are not optimistic. Many people write business letters, reports, proposals and other texts without reading any advisory book at all. Many writers try to invent an appropriate macrostructure for their text without considering a standard structure described in a textbook.

Perhaps the paramount matter is not whether writers will detect problems, but when they will detect them and what problems will be detected. Their need for advice will possibly vary with the activities they are involved in. We can make a distinction between three stages of the writing process where advice probably will be needed: the initial planning stage, the formulation stage, and the revision/ editing stage. ${ }^{2}$

During the initial planning stage, we expect that writers will need advice on macrostructural aspects of the text, such as a text model that describes which elements have to be included in a particular genre of text, or some hints for the general style to be chosen in such a text. Information of this kind should be linked to some notions of the functions of the text, i.e., an indication of the intended audience, its information needs and its expected usage of the text. It might also be important to provide information on conventions applying to the text genre.

Using CATS during the planning stage could also be beneficial if writers are restricted to strict specifications for content, structure, form, wording, or other aspects of the text. Especially where issues are not routine, online documentation may be convenient. Then, it might be worthwhile to include all kinds of norms, rules and prescriptions, gathered form ISO, DIN, NEN, and other standards. It would also be helpful to include special norms and matters related to the writer's own company. With respect to this, it is important to note that the content of a CATS help system can easily be modified and adapted to individual needs.

An interesting question is whether writers are likely to activate CATS during the formulating phases of the writing process. It is frequently assumed that

\footnotetext{
${ }^{2}$ This formulation may suggest that writing is a linear process, where these three stages are processed after each other. In fact, writing is a highly recursive process, where planning, formulating and revision alternate frequently. But this issue is not directly relevant to our argument.
} 
are included in the index or in the keyword list. Perhaps this approach may also work for some topics other than spelling and morphology. For instance, a keyword like dear could give access to the guidelines for the opening of a letter.

Writers might use this example-strategy in CATS successfully as a result of the full text search facility. If common textbook examples are added to the guidelines and recommendations in CATS, there will be an increased chance that users will find the information they need.

\section{SUMMARY AND CONCLUSIONS}

In this article we have sketched the development of a relatively new tool for writers: an online advisory system. Such a system could have considerable advantages compared to traditional "paper" textbooks, reference books, guides, and norms: the online information can be consulted much faster, it can be more comprehensive than even a bookshelf full of documents, it can be kept up-to-date, and it can be easily adapted to the special needs of the organization or the individual user.

Although results of first experiments are encouraging, we are not yet fully convinced that CATS will be an adequate solution to all writers' problems. More research is needed into the successive stages of information seeking, in order to understand the difficulties and barriers writers can meet consulting CATS. Such research will hopefully yield two outcomes: a deeper insight in information seeking behavior and good ideas for improving CATS.

The latter result will be of special relevance since the Netherlandse Taalunie (Dutch Language Union) $)^{3}$ has decided to use CATS as the technical environment for a linguistic database, containing recommendations and guidelines on Dutch grammar and style, extracted from a broad range of publications. This database should be completed before the end of 1995, and is expected to become a universal and authoritative information source for all Dutch language users.

\section{REFERENCES}

1. L. Lentz and D. de Vet, Tekstschrijver als beroep (Text Writer as a Profession), Communicatief, 5:1, pp. 3-11, 1993.

2. C. Jansen, Computerized Writing Aids: Do They Really Help? in Quality of Technical Documentation, M. F. Steehouder et al. (eds.), Utrecht Studies in Language and Communication, Vol. 3, Rodopi, Amsterdam/Atlanta, 1994.

3. M. Schneider and P. Tanis, Solliciteren met CATS. Onderzoek naar de bruikbaarheid van de adviezen die het schrijfadviessysteem CATS geeft t.a.v. het schrijven van een sollicitatiebrief (Applying for a Job with CATS. A Study of the Usability of the Recommendations for

${ }^{3}$ The Nederlandse Taalunie is an official institute, established by the Dutch government and the Flemish government to advice about issues concerning language policy in both countries. 


\section{Locating the Information}

The different ways users name their writing problems is important for the design of the access structure in CATS. The enormous number of false keywords in both the Vernoy study and the Nas study indicate that the proved method of adding synonyms to an index is not a sufficient solution. Other access structures are needed. However, menus, content lists, and glossaries seem to have the same disadvantage as an index: the user has to know the appropriate keywords to use these features successfully.

One promising feature, though, is the use of hyperlinks to connect sections of the online document with each other. If a user arrives in a section which is not exactly relevant to the problem, there is a fair chance that one or more hot spots will offer a good idea for further searching. However, hyperlinks also have some disadvantages.

First, sooner or later the user may get lost in hyperspace: he gets distracted by information which is not directly relevant but which nevertheless is interesting. Many users cannot resist the temptation to activate a hot spot and to make an excursion, and another one, and so on. At the end they get lost: they don't know where in the information system they are.

Another risk of hyperlinks might be that the user keeps on searching for something which cannot be found, because it's not there. This mechanism is observed by Kegel et al. comparing an online help system with hyperlinks and a system without hyperlinks [8]. As could be expected, users often chose inappropriate keywords for their problems. Those who used the system without hyperlinks discovered fairly soon that a keyword would not bring them further, and tried to come up with another one. Those who used the hypertext system, however, kept on searching, hoping that one way or another they would find something; they continued with their original keyword.

A useful facility to help users who get lost in hyperspace might be the history utility - standard in Windows help—which provides a list of all sections the user has consulted, and offers the possibility to return easily to a previous section. In addition, CATS offers the possibility to go to a complete, hierarchically, structured content list providing an overall picture of the help document, a feature which might help the user become re-oriented.

Besides hypertext, there might be another way to overcome the keyword problem. Vernoy, investigating the names that were given to linguistic errors by writers who were not linguistics, discovered that many of these errors were named after a characteristic example [6]. For instance, many subjects did not opt for official linguistic terms such as "plural forms," but characterized their problem as "a problem like beide/beiden," which can be considered as the "textbook example" for a plural form problem.

This naming strategy-which probably is very common in matters of morphology and spelling-can be honored by CATS if such characteristic examples 
Writing Application Letters, Provided by the Writing Advisory System CATS), unpublished paper, Centre for Language and Communication, Utrecht University, 1993.

4. P. Tanis, Online schrijfadviezen in hypertekst. Een onderzoek naar de vormgeving van het schriffadviesprogramma CATS (Online Guidelines for Writers. A Study of the Design of the Writing Advisory System CATS), unpublished paper, Centre for Language and Communication, Utrecht University, 1993.

5. M. Steehouder, The Quality of Access: Helping Users Find Information in Documentation, in Quality of Technical Documentation, M. F. Steehouder et al. (eds.), Utrecht Studies in Language and Communication, Vol. 3, Rodopi, Amsterdam/Atlanta, 1994.

6. M. Vernoy, Experimenteel onderzoek probleemherkenning en representatie (Experimental Study on Problem Recognition and Representation), unpublished report, Centre for Language and Communication, Utrecht University, 1993.

7. G. Nas, Collecting Descriptions of Text Processing Problems for a User Friendly Manual, in Quality of Technical Documentation, M. F. Steehouder et al. (eds.), Utrecht Studies in Language and Communication, Vol. 3, Rodopi, Amsterdam/Atlanta, 1994.

8. S. Kegel, M. Sienot, and A. van der Wal, De effectiviteit van twee soorten online documentatie (The Effectiveness of Two Types of Online Documentation), unpublished paper, Centre for Language and Communication, Utrecht University, 1994.

\section{Other Articles on Communication By These Authors}

Jansen C. and M. Steehouder, Improving the Text of a Public Leaflet, Information Design Journal, 4, pp. 10-18, 1984.

Jansen, C. J. M., M. F. Steehouder, A. Pilot, D. Schrauwen, and P. J. M. Looijmans, ALEXIS: Computer-assisted Feedback on Written Assignments, Computer and Composition, 4, pp. 32-45, 1986.

Steehouder, M. and C. Jansen, From Bureaucratic Language to Instructional Texts: How to Design an Effective Problem-solving Tool for Citizens, Information Design Journal, 5, pp. 129-139, 1987.

Steehouder, M. and C. Jansen, Optimizing the Quality of Forms, in Studies in Functional Text Quality, H. Pander Maat and M. F. Steehouder (eds.), Editions Rodopi, Amsterdam, pp. 159-172, 1992.

Jansen, C. and M. Steehouder, Forms as a Source of Communication Problems, Journal of Technical Writing and Communication, 22, pp. 179-194, 1992.

Steehouder, M., C. Jansen, P. van der Poort, and R. Verheijen (eds.), Quality of Technical Documentation, Rodopi, Amsterdam/Atlanta, Georgia, 1994.

Direct reprint requests to:

Carel Jansen

Centre for Language and Communication

Utrecht University

Trans 10

3512 JK Utrecht

The Netherlands 